\title{
PROGRESSIVE COLLAPSE RESISTING MECHANISMS OF REINFORCED CONCRETE STRUCTURES
}

\author{
Kamal Alogla ${ }^{(*)}$, Laurence Weekes, Levingshan Augusthus-Nelson \\ School of Computer Science and Engineering, University of Salford, Manchester, United Kingdom \\ ${ }^{(*)}$ Email: k.d.alogla@edu.salford.ac.uk
}

\begin{abstract}
Reinforced concrete (RC) buildings may be vulnerable to progressive collapse due to lack of sufficient continuous reinforcement. Progressive collapse is a situation when local failure is followed by collapse of adjoining members, which in turn causes global collapse, and can eventually result in injuries or loss of life. Design of structures against progressive collapse has not been an integral part of structural design. However, some guidelines such as General Service Administration (GSA) and Unified Facilities Criteria (UFC) guidelines have detailing requirements to reduce the likelihood of progressive collapse. It is difficult to predict the structural behaviour of building members during progressive collapse because the dynamic nature of the event and the limited experimental tests conducted to understand the nature of progressive collapse. Membrane action of beams and floors are important mechanisms of load redistribution and progressive collapse resistance in the event of failure of load-bearing elements. The behaviour of reinforced concrete beams under compressive and tensile membrane action is not yet fully understood.
\end{abstract}

In order to investigate and quantify the structural resisting mechanisms of reinforced concrete structures against progressive collapse, two large scale specimens have been tested under quasi-static loading. Non-linear response is then converted into dynamic response (PseudoStatic response) using the energy equilibrium approach proposed by Izzuddin et al. (Izzuddin et al., 2008)

A finite element model was developed using the finite element software package ANSYS 11.0 in order to numerically simulate structural behaviour of RC beam-column subassemblages when load-carrying members are removed under the effect of abnormal loading. A macro-model based approach was used in the finite element analysis by using beam elements and a series of spring non-linear elements to capture the non-linear behaviour of structural members associated with the redistribution of loads after column removal. Numerical results were compared with those obtained from the experimental program. Test results showed that the RC sub-assemblages would experience three mechanism stages, flexural, compressive arch and catenary action stages to resist progressive collapse. Numerical results showed a good agreement with the experimental results.

Keywords: Progressive collapse, reinforced concrete, compressive arch action, catenary action, finite element analysis.

\section{INTRODUCTION}

Progressive collapse is a situation when local failure is followed by collapse of adjoining members, which in turn causes global collapse, and can result in injuries or loss of life. Design of structures against progressive collapse has not been an integral part of structural 
design. However, some guidelines such as General Service Administration (GSA, 2003) and Unified Facilities Criteria Department of Defence (DOD, 2004) guidelines have detailing requirements to reduce the likelihood of progressive collapse by altering the load path. The main approach to improve the structural resistance against progressive collapse is to increase redundancy and continuity in a structure, and ductility of a structural member. Redundancy will allow the structure to redistribute the load from the part of a structure which has lost structural integrity to an alternative load path with remaining structural integrity. This can only be achieved though continuity of the structure and the provision of adequate ductility. To mitigate progressive collapse, efforts have been directed at both code provisions and research work.

In general code provisions, structural integrity reinforcement is required to improve redundancy and ductility in structures. To achieve continuity in structural components, tie forces are required to tie the elements together so they act as one unit. When one of the critical load bearing elements is damaged or removed, connecting spans deflect until rotational capacity provided by the adjacent beams or slabs is exhausted. Then, catenary action may allow the beam to carry vertical loads at large displacements. Catenary action is considered as the last line of defence for a structure to mitigate progressive collapse when a load bearing element is removed or damaged. Regan (Regan, 1975) concluded that the successful development of a catenary action requires that the members in question possess not only tensile strength but also ductility, which is largely determined by the detailing of the longitudinal reinforcement. The beam above a removed column undergoes three stages of mechanisms, flexural action (FA), compressive arch action (CAA) and catenary action (CAT). Initially, all beams mobilize flexural action, which they are designed for and they are able to sustain the design load. When a column is removed, the span of the beam doubles and in most cases leads to large deflection occur in the beam. Compressive arch action, which enhances the flexural strength at critical sections, can be mobilized in the presence of axial compression provided by strong lateral restraints. At large deflections catenary action can be mobilized. Orton (Orton, 2007) found that catenary action will not begin until the beam has reached a deflection equal to the depth of the beam. There are very few previous studies on catenary action of reinforced concrete beams and most of the experimental studies are concerned with catenary action of steel beams at ambient and elevated temperatures and under column loss scenarios (Byfield et al., 2007, Byfield and Paramasivam, 2007, Izzuddin, 2005, Yin and Wang, 2005). Quasi-static tests were conducted to demonstrate the structural behaviour of RC sub-assemblages subjected to column removal scenarios (Choi and Kim, 2011, Sadek et al., 2011, Sasani and Kropelnicki, 2008, Su et al., 2009, Yi et al., 2008, Yu and Tan, 2013). An experimental study of structural response of two RC sub-assemblages under column removal scenario (CRS) will be presented.

\section{EXPERIMENTAL PROGRAM}

Based on the alternate load path approach, a series of specimen tests have been carried out to investigate progressive collapse resistance mechanisms and their capacities for RC beamcolumn sub-assemblages under CRS. Figure 1 shows the effect of column removal on a typical building. As seen in Figure 1, the bending moment significantly increases (approximately 4 times) due to doubling the span. Furthermore, the moment over the missing column reverses direction, positive where the beam was designed for negative moment. All these changes may not be considered in conventional design. 

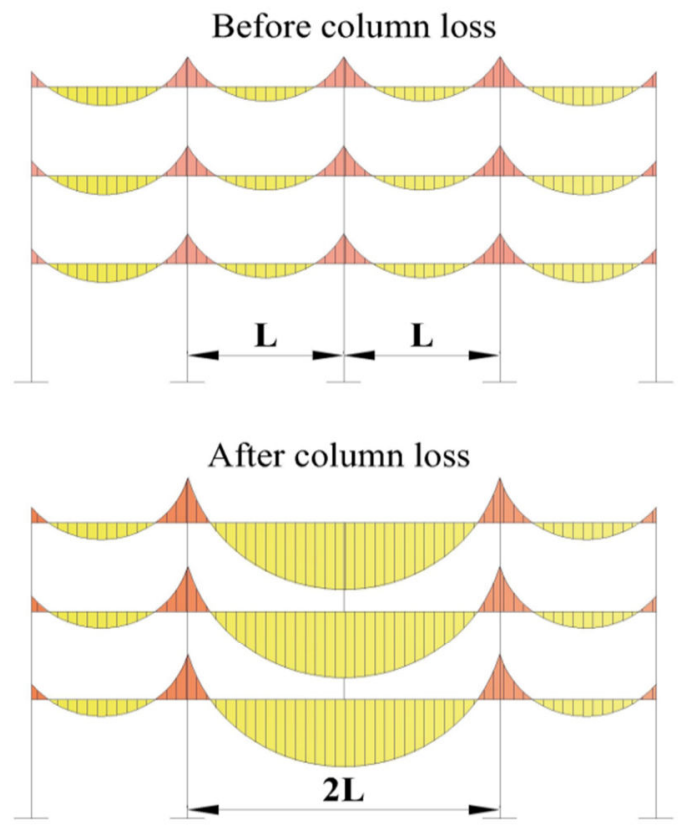

Fig. 1 - Moment distribution of typical structure before and after column removal

\section{DESIGN OF SPECIMEN}

The specimen is assumed to be extracted from the middle of a multi-storey, multi-bay frame building. Figure 2 shows part of a structure with the shaded area being directly affected by a removed column which represents the test specimen. A prototype frame building was designed and detailed according to ACI 318-05 (ACI-318, 2005) for non-seismic regions. The specimen was then scaled down to one-half of the prototype frame. Figure 3 shows the dimensions and detailing of a typical specimen.

\section{TEST SETUP AND INSTRUMENTATION}

Figure 4 shows a schematic view of the test rig. To simulate the axial horizontal restraint for the beams, the ends of the specimens were connected to a steel frame by two load cells at each end, and these load cells were used to measure the horizontal forces that developed through the specimen during the test. In the vertical direction, a hinge roller support was used to restraint each end of the specimen. The reason for using a hinge roller support was to reduce the effect of the vertical reaction on the horizontal reaction in order to make the vertical and horizontal reactions independent of each other.

The load cells used to measure the reactions in the horizontal direction have the ability to measure compression and tension forces with a carrying capacity of $250 \mathrm{kN}$ each. The load was applied at the top of the middle joint using a hydraulic actuator with displacement control until total failure of the specimens. The actuator with a built-in load cell was attached into a steel frame fixed into the strong floor of the structural laboratory. A steel plate and roller was used to support the bottom of each of the end column stubs. Because the specimens were slender, a lateral steel restraint was installed near the centre of the specimens to prevent outof-plane movement as shown in Figure 5. It was designed that the end column stubs do not fail and the adjacent frames have sufficient lateral stiffness to provide lateral restraint at both CAA and catenary action. 


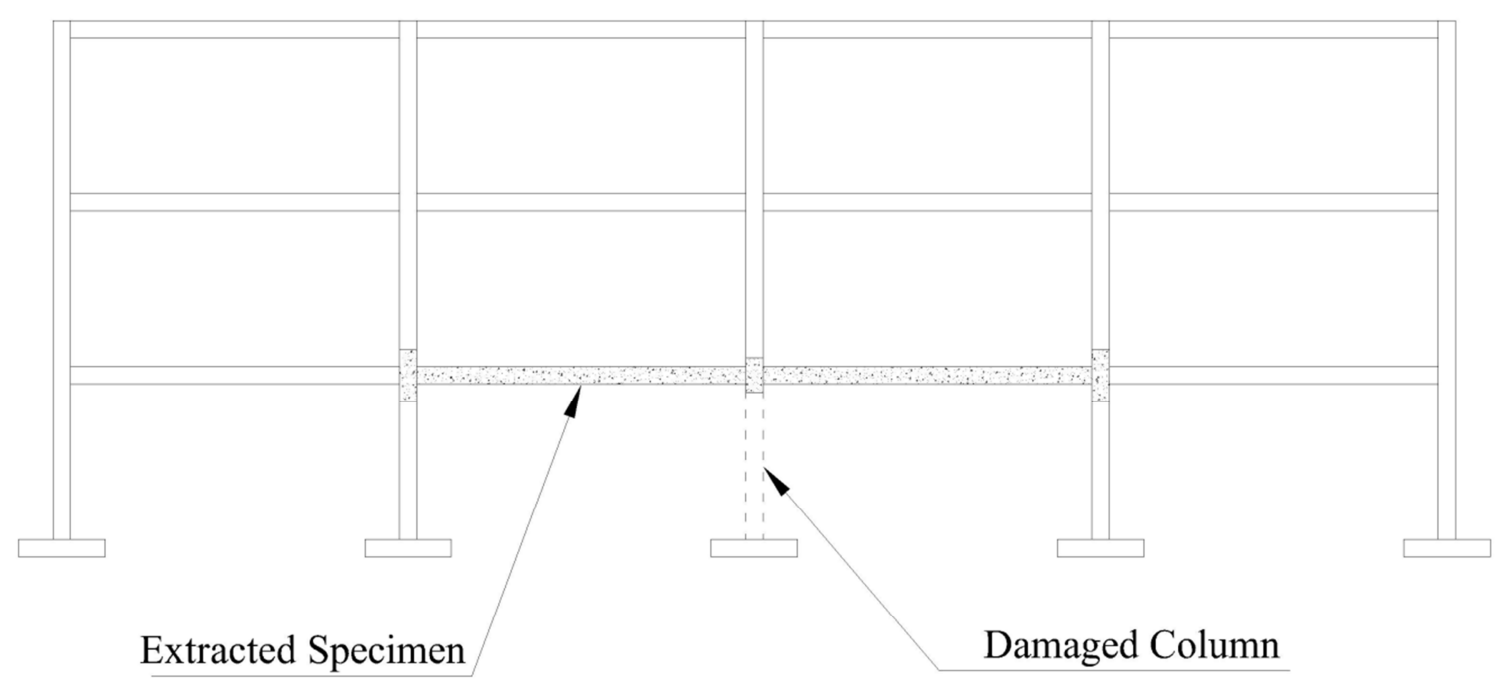

Fig. 2 - Elevation of test specimen within the building structure
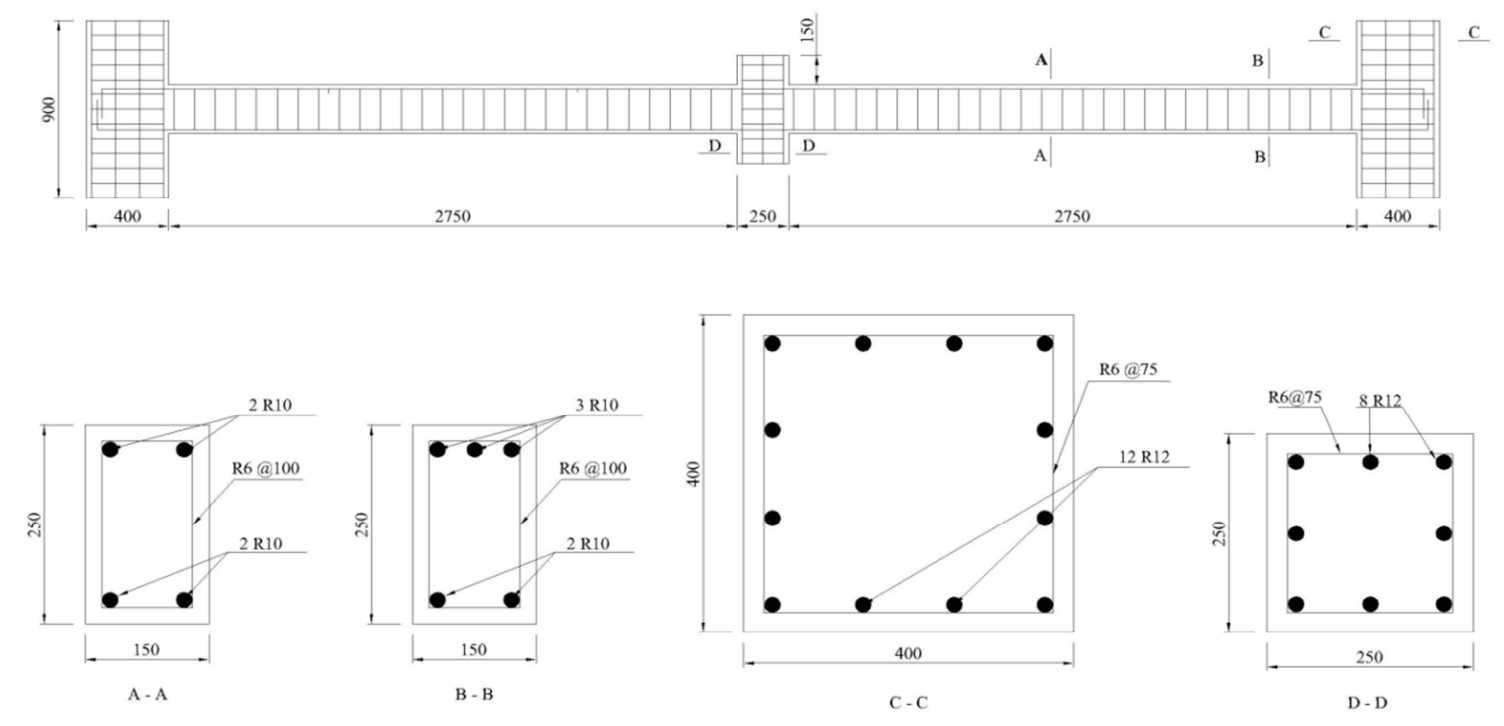

Fig. 3 - Conventional specimen dimensions and reinforcement details (all dimensions are in $\mathrm{mm}$ )

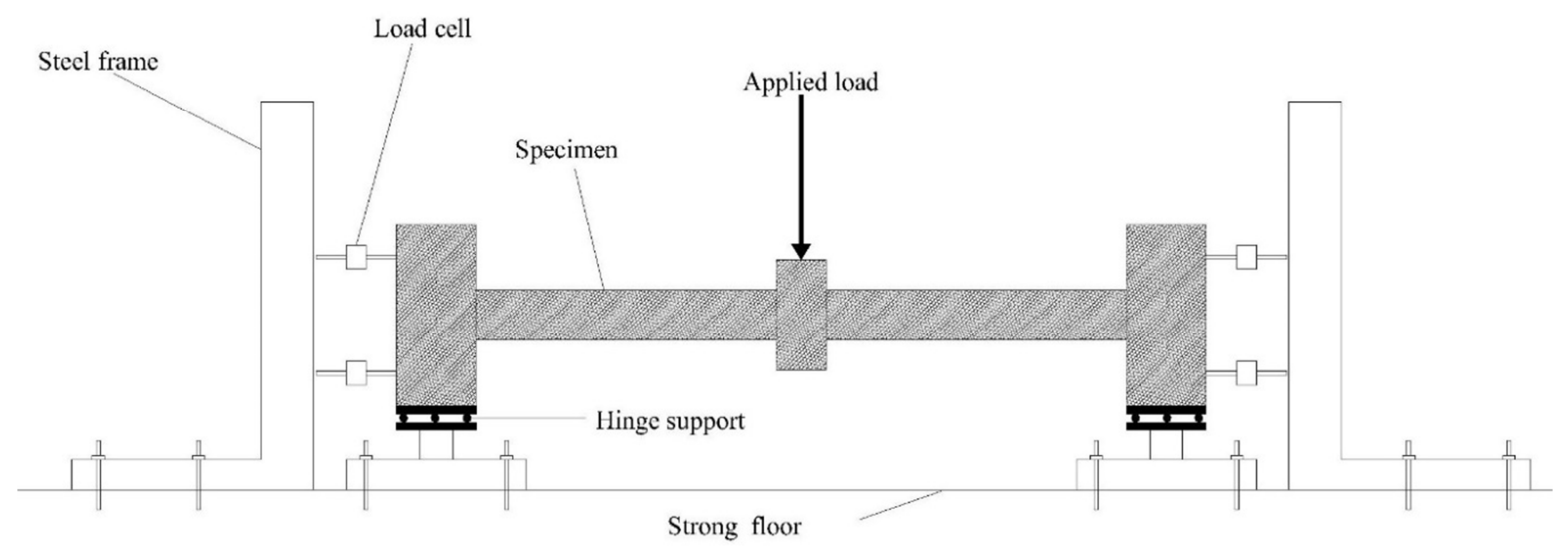

Fig. 4 - Schematic view of the test specimen and test rig 


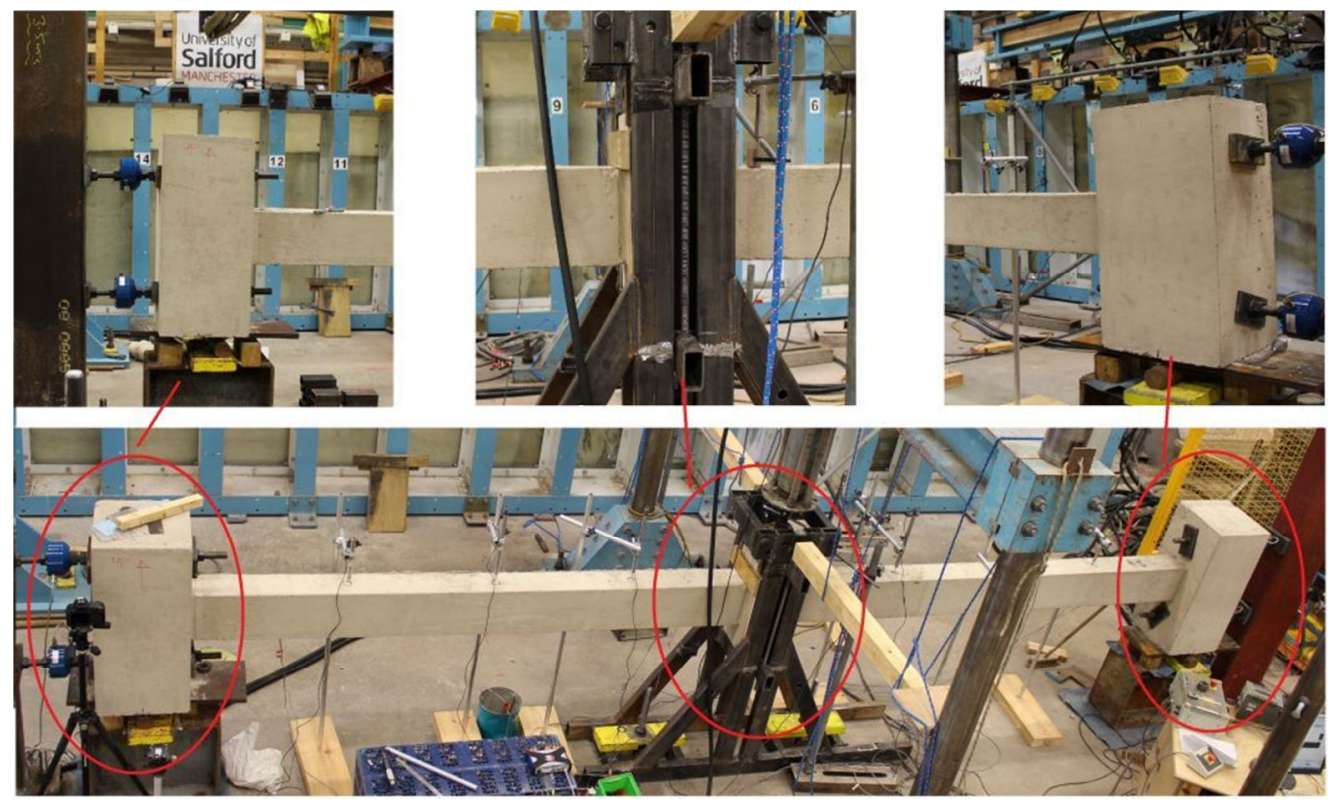

Fig. 5 - Test rig restraints

The RC sub-assemblage specimens were mounted with measuring instruments both internally and externally. The applied load imposed by the actuator was measured using an in-built load cell which was connected in series with the hydraulic actuator jack. Seven external linear variable differential transformers (LVDT) were mounted along the specimen to measure vertical displacement along the length of the specimens. Four load cells were attached to the column stubs at the ends of specimen to measure axial forces developed during the tests. These load cells have the ability to measure tension and compression forces. Figure 6 shows the lay-out of instrumentations along half of the sub-assemblage

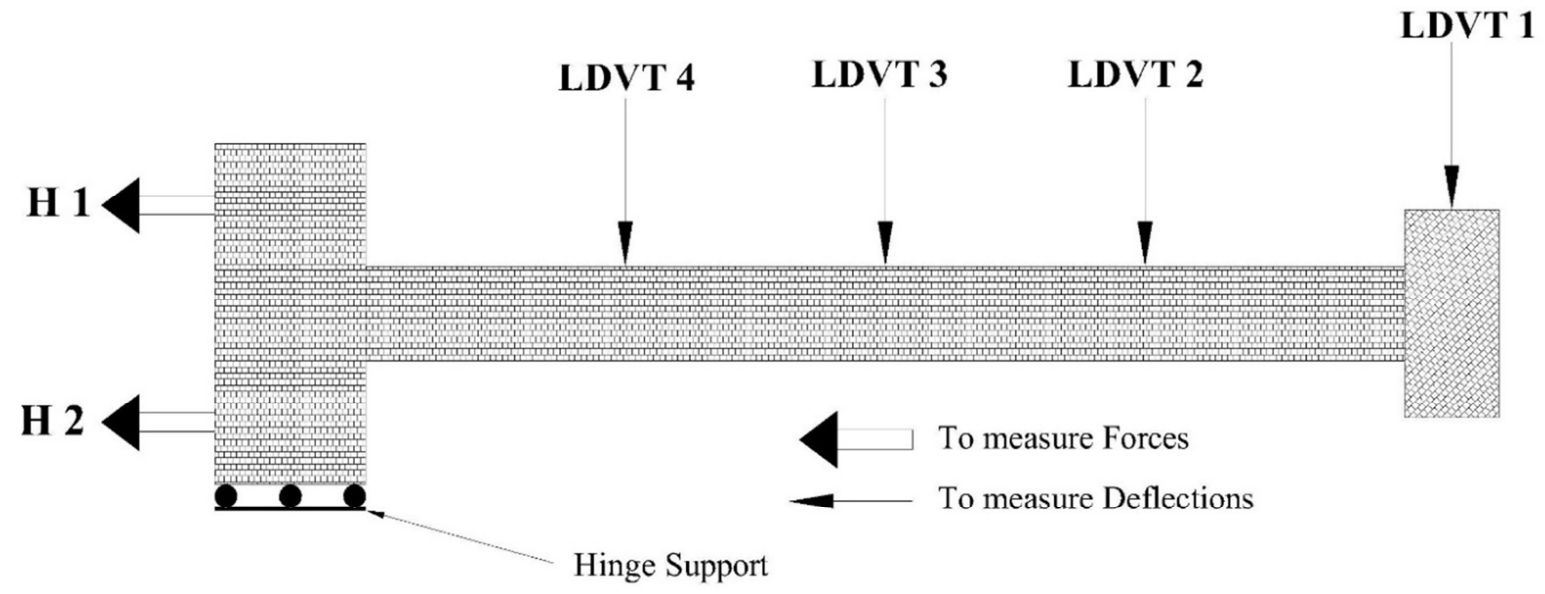

Fig. 6 - Arrangement of instrumentation along half of test specimen

In order to monitor the development of internal stresses and forces for different structural mechanism phases, strain gauges were installed on the longitudinal steel reinforcement and attached at critical sections, such as the faces of joints. Figure 7 shows the layout of strain gauges and their locations in the sub-assemblage specimens. 
(a)

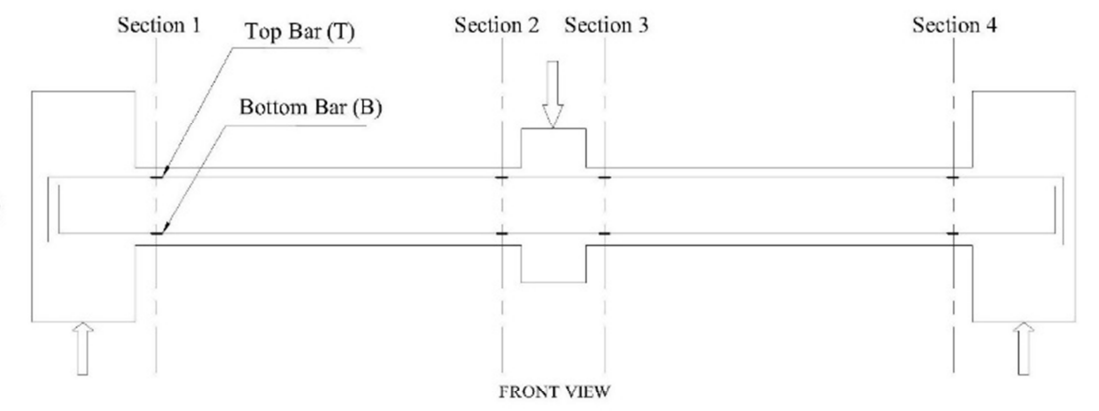

(b)

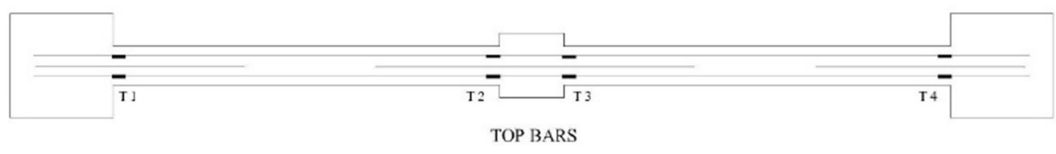

(c)

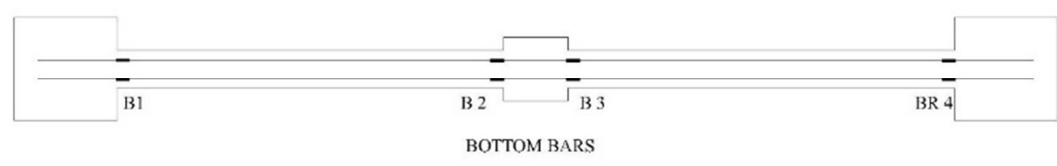

Fig. 7 - Locations of strain gauges (a) front view, (b) top bars and (c) bottom bars

\section{TEST PROCEDURE}

The load was applied using a hydraulic actuator with a monotonic loading regime until total failure of the specimens. During the test, all reaction forces at each side indicated as $\mathrm{H} 1$ and $\mathrm{H} 2$ as shown in Figure 6 were measured using load cells, and the applied load was measured using the in-built load cell of the actuator. The displacement at the middle joint and along the length of the beam was measured by using linear displacement transducers as shown in Figure 6. Therefore, the beam deflection at each load step could be determined, and axial forces developed through the beam could be calculated for each deflection value corresponding to each load step. In addition, strain gauges, which were attached to the steel reinforcement, measured the strain in the steel bar at each load step. These strains can be converted into stresses and then to forces, which indicate the development of each resisting mechanisms such as flexural action, compressive arch action and catenary action.

The test data and results were collected and recorded simultaneously at a sampling rate of 1.0 $\mathrm{Hz}$ using an MTS data acquisition system.

\section{MATERIAL PROPERTIES}

The construction and casting of the specimens was divided into two batches. Each sample was cast in a single batch. During the process of casting, three concrete cubes of dimension $100 \mathrm{x}$ $100 \times 100 \mathrm{~mm}$ were sampled to obtain concrete compressive strength. One cylinder of dimension $300 \mathrm{~mm}$ height and $150 \mathrm{~mm}$ diameter was sampled and tested to obtain modulus of elasticity. One prism of dimension $400 \times 100 \times 100 \mathrm{~mm}$ was sampled to obtain modulus of rapture. The compressive strength test of concrete was carried out in accordance with BS1881-116 (BS1881-116, 1983 ). Modulus of elasticity and Modulus of rapture were carried out in accordance with ASTM, C469-02(ASTM, 2002) and ASTM, C78-09 (ASTM, 2009) respectively. 
According to the specimen design, the targeted concrete compressive strength at 28 days was $28 \mathrm{MPa}$. Each set of cubes was tested at the day of specimen test and the average compressive strength of the three cubes was taken as listed in Table 1.

For steel reinforcing bars, three samples of longitudinal bars were tested in tension. Steel reinforcement propertied are listed in Table 2.

Table 1 - Concrete mechanical properties

\begin{tabular}{|c|c|c|c|}
\hline Specimen & $\begin{array}{c}\text { Average Compressive } \\
\text { Strength } \\
\text { Mpa }\end{array}$ & $\begin{array}{c}\text { Modulus of Elasticity } \\
\text { Mpa }\end{array}$ & $\begin{array}{c}\text { Modulus of Rapture } \\
\text { Mpa }\end{array}$ \\
\hline SS-1 & 26.8 & 23120 & 2.9 \\
\hline SS-2 & 28.5 & 24450 & 3.1 \\
\hline
\end{tabular}

Table 2 - Steel properties

\begin{tabular}{|c|c|c|c|c|c|c|}
\hline $\begin{array}{c}\text { Steel } \\
\text { Type }\end{array}$ & $\begin{array}{c}\text { Yield } \\
\text { Strength } \\
\text { Mpa }\end{array}$ & $\begin{array}{c}\text { Yield } \\
\text { Strain }\end{array}$ & $\begin{array}{c}\text { Elastic } \\
\text { Modulus } \\
\text { Mpa } \\
f_{\boldsymbol{y}}\end{array}$ & $\begin{array}{c}\text { Ultimate } \\
\text { Strength } \\
\text { Mpa } \\
E_{\boldsymbol{s}}\end{array}$ & $\begin{array}{c}\text { Ultimate } \\
\text { Strain }\end{array}$ & $\begin{array}{c}\text { Hardening } \\
\text { Modulus } \\
\text { Mpa } \\
\text { T10 }\end{array}$ \\
\hline 510 & 0.0026 & 196154 & 650 & 0.13 & 1099 \\
\hline
\end{tabular}

\section{TEST RESULTS AND DISCUSSIONS}

In this section, experimental test results will be presented and illustrated at both global and local levels. Test results at the global level include the relationship between applied load and middle joint displacement, axial forces and middle joint displacement and failure mode and crack pattern. Test results at local level include the relationship of bar strains at critical sections with middle joint displacement. Moreover, test results will be differentiated and categorized according to the resistance mechanism for three stages: flexural, compressive arch action and catenary action.

For a building, the usual terminology is such that global refers to the whole building system, while local refers to each structural member individually. For the following sections, global will refer to the structural behaviour of the specimen, while local will refer to the internal forces that developed during the test.

\section{TEST RESULTS AT GLOBAL LEVEL}

The overall structural behaviour of $\mathrm{RC}$ specimens is described by the relationships of the applied load versus vertical deflection and the axial forces developed versus vertical deflection. The deflected shape of the specimens can be illustrated by the deflection at specific points along the length of the beam at different stages of loading. Figure 8 shows the deflection curves of the specimens at specified load steps. 


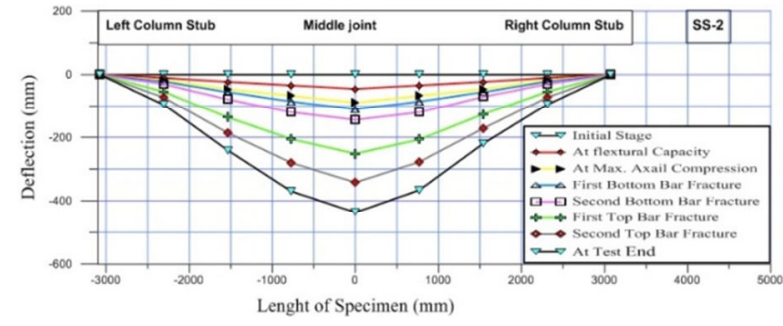

(a)

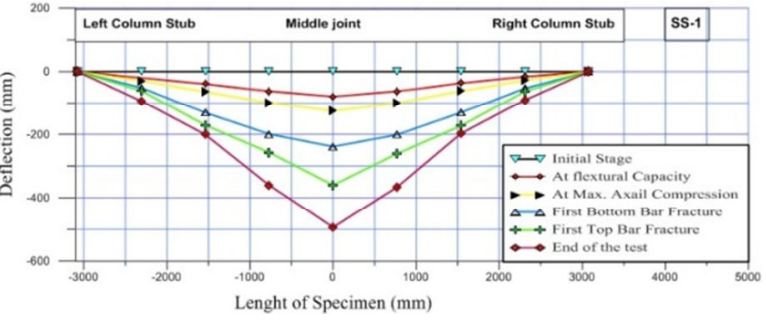

(b)

Fig. 8 - Beam deformation for (a) SS-1 and (b) SS-2.

It can be seen from Figure 8 that the specimens were deflected symmetrically about the middle joint. Also it can be observed that there is a large difference in displacement between the stage of bottom bar fracture (at the middle joint) and top bar fracture (at the ends). This can be related to the formation of plastic hinges at the middle joint, which caused large deflections at that stage.

Figures 9 and 10 show the relationships of applied load vs. middle joint displacement and axial force vs. middle joint displacement for specimens SS-1 and SS-2 respectively. Table 3 lists forces and their corresponding middle joint displacements at critical stages of loaddeflection history.

The general trend of the load-displacement history can be divided into three stages, flexural action, compressive arch action and catenary action as shown in Figure 9. The overall trends of the load-displacement relationship for specimens SS-1 and SS-2 were quite similar despite that they have different concrete strengths, which results in different flexural capacity as can be seen from Figure 9. The peak flexural capacities were 34.0 and $34.9 \mathrm{kN}$ for SS-1 and SS-2 respectively. After the peak loads were reached, plastic hinges were developed and bar fracture occurred. The abrupt drops in the applied load shown in Figure 9 were due to subsequent fracture of steel reinforcing bars at the bottom and top of the beam section respectively.

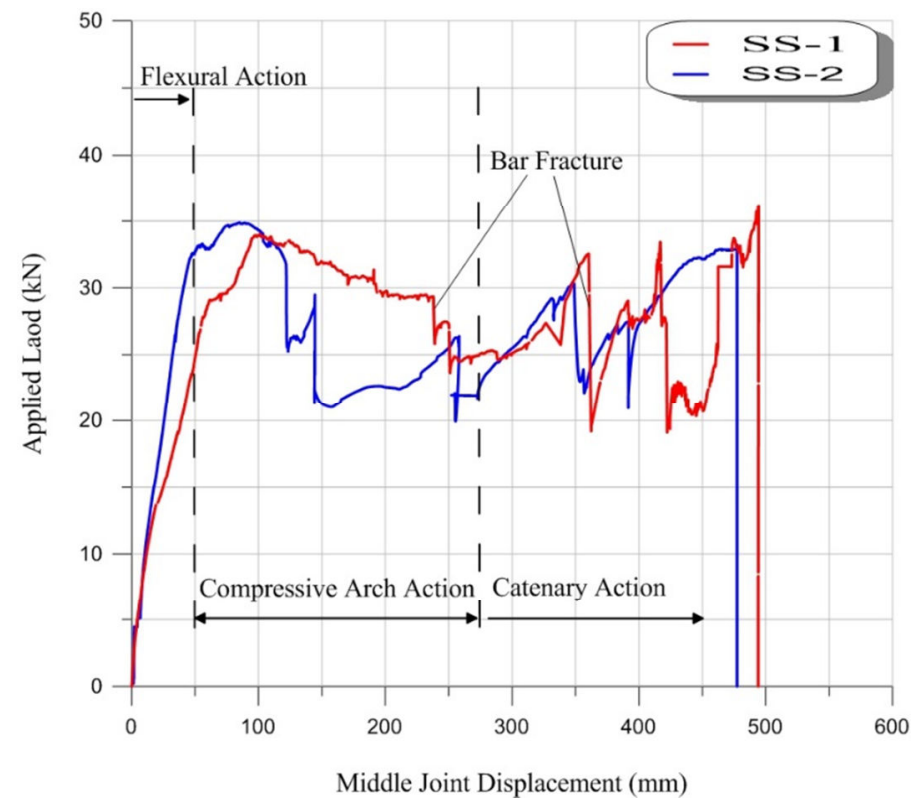

Fig. 9 - Applied Load vs. Middle Joint Displacement relationship of SS-1 and SS-2. 
As shown in Figure 10 there is no separation point between flexural action and compressive arch action due to the fact that the compressive arch action developed at the beginning of the loading in axially restrained members. On the other hand, it is clear from Figure 10 that the transition point from compressive arch action to catenary action occurred only when axial loads changed from a compression force to a tension force. For SS-1 and SS-2, the catenary action started to develop at a middle joint displacement of $272.5 \mathrm{~mm}$ and $246 \mathrm{~mm}$ respectively.

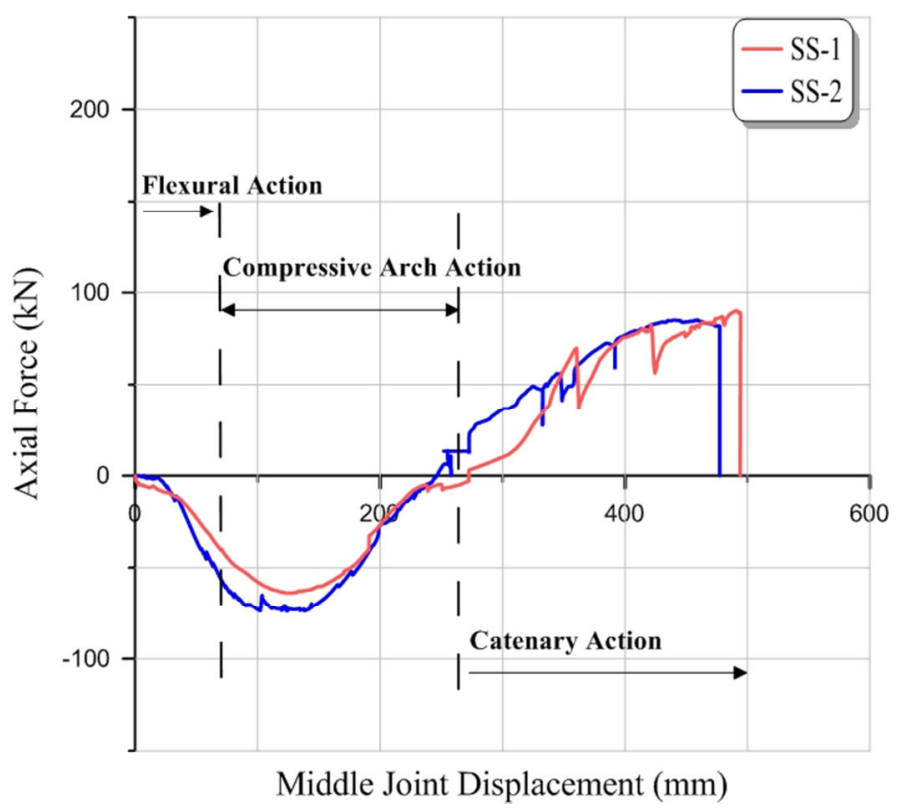

Fig. 10 - Axial Force vs. Middle Joint Displacement relationship of SS-1 and SS-2.

It is clear from Table 3 that the experimental flexural capacities (Maximum load at CAA) were larger than the calculated flexural capacities. This is because the development of axial compression force through the beam occurred in the early stages of loading where flexural action is assumed to dominate. At this stage, axial compression is not considered in the calculation of flexural capacity for the beam section.

Table 3 - Forces with their MJD's at critical stages

\begin{tabular}{|c|c|c|c|c|c|c|c|c|c|c|}
\hline \multirow{2}{*}{$\begin{array}{l}\text { Spec- } \\
\text { imen }\end{array}$} & \multicolumn{2}{|c|}{$\begin{array}{c}\text { Calculated } \\
\text { flexural capacity }\end{array}$} & \multicolumn{2}{|c|}{$\begin{array}{l}\text { Maximum load } \\
\text { at CAA }\end{array}$} & \multicolumn{2}{|c|}{$\begin{array}{l}\text { Maximum axial } \\
\text { compression } \\
\text { force }\end{array}$} & \multicolumn{2}{|c|}{$\begin{array}{l}\text { Maximum axial } \\
\text { tension force }\end{array}$} & \multicolumn{2}{|c|}{$\begin{array}{l}\text { Maximum load } \\
\text { at catenary } \\
\text { action }\end{array}$} \\
\hline & $\begin{array}{c}P_{f} \\
(\mathrm{kN})\end{array}$ & $\begin{array}{l}\text { MJD } \\
(\mathrm{mm})\end{array}$ & $\begin{array}{l}P_{\text {com }} \\
(\mathrm{kN})\end{array}$ & $\begin{array}{l}\text { MJD } \\
(\mathrm{mm})\end{array}$ & $\begin{array}{l}N_{\text {com }} \\
(\mathrm{kN})\end{array}$ & $\begin{array}{l}\text { MJD } \\
(\mathrm{mm})\end{array}$ & $\begin{array}{l}N_{\text {ten }} \\
(\mathrm{kN})\end{array}$ & $\begin{array}{l}\text { MJD } \\
(\mathrm{mm})\end{array}$ & $\begin{array}{l}P_{\text {cat }} \\
(\mathrm{kN})\end{array}$ & $\begin{array}{l}\text { MJD } \\
(\mathrm{mm})\end{array}$ \\
\hline SS-1 & 28.0 & 57.9 & 34.0 & 101.0 & 63.8 & 125.6 & 89.2 & 494.0 & 36.2 & 494.0 \\
\hline SS-2 & 29.8 & 40.4 & 34.9 & 89.3 & 74.1 & 123.9 & 85.1 & 459.7 & 33.2 & 477.3 \\
\hline
\end{tabular}

After the compressive arch action attained its maximum capacity catenary action started to develop after the middle joint vertical displacement surpassed the beam depth. The stage at which catenary action started to develop was after the fracture of bottom reinforcements at the middle joint, which means that the catenary action utilized the top bars in the middle joint. As the MJD increased further, the top reinforcements at the beam ends fractured, which is shown 
in Figure 9. At that stage, catenary action depends on the bottom reinforcements at the beam ends.

As can be seen in Table 3, the maximum tensile forces at catenary action for the specimens were quite similar, which means that the tensile forces depend only on the steel reinforcement. On the other hand, the large deformation for SS-1 may be related to the concrete strength and the crushing of concrete at the bottom fiber of the beam ends.

The overall crack pattern and failure mode between the specimens were quite similar. At the flexural action stage, the cracks were concentrated at the beam-column joint interfaces as shown in Figure 12, which are mainly caused by bending moments at these sections.

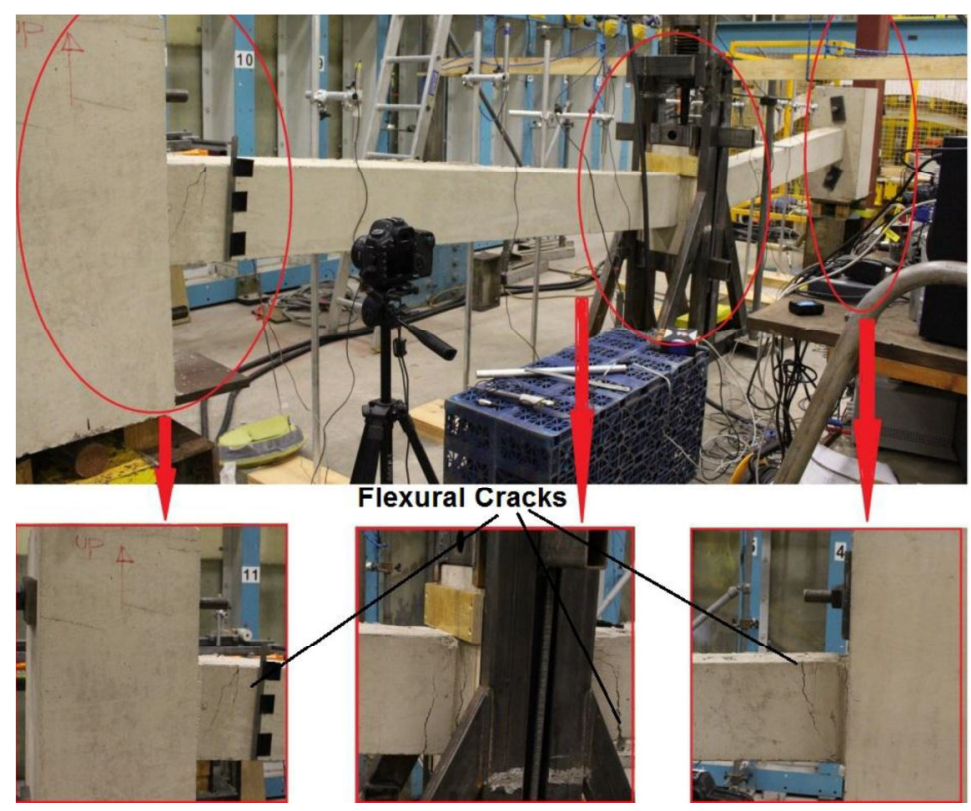

Fig. 11 - Crack pattern of specimen SS-1 at flexural action

The flexural cracks (developed during flexural action) futher extented vertically away from concrete tension face and terminated at the location of neutral axis. As the applied load increased, the neutral axis moved towards the compression face until the concrete crushed at the extreme surface in the compression zone. Different from flexural action, cracks started to develop throughout the beam length and passed completely through the beam section during the catenary action as shown in Figure 12. With the increase of the applied load, cracks width are increased and bar fracture occurred at the beam-column joint interfaces. It is worth mentioning, at catenary action the cracks were uniformly distributed along the beam length and a large slip between steel bars and concrete was observed at the beam-column joint interfaces.

In order to obtain progressive collapse capacity under abrupt condition, the non-linear static structural behaviour('quasi-static response') should be converted to non-linear dynamic behaviour. The proposed approach by Izzuddin et al. (Izzuddin et al., 2008) was used to obtain progressive collapse capacity. This approach is based on energy equilibrium, which states that for the structure to be stable, the work done by applied gravity loads should be equal to the energy absorbed by the structure. In other words, the structure should have enough strain energy supply to absorb any energy demand caused by sudden loss of vertical support. The converted non-linear dynamic behaviour is called the 'pseudo-static' structural behaviour. Figures 13 (a) and (b) show the pseudo-static structural behaviour of specimens SS-1 and SS-2 respectively. 


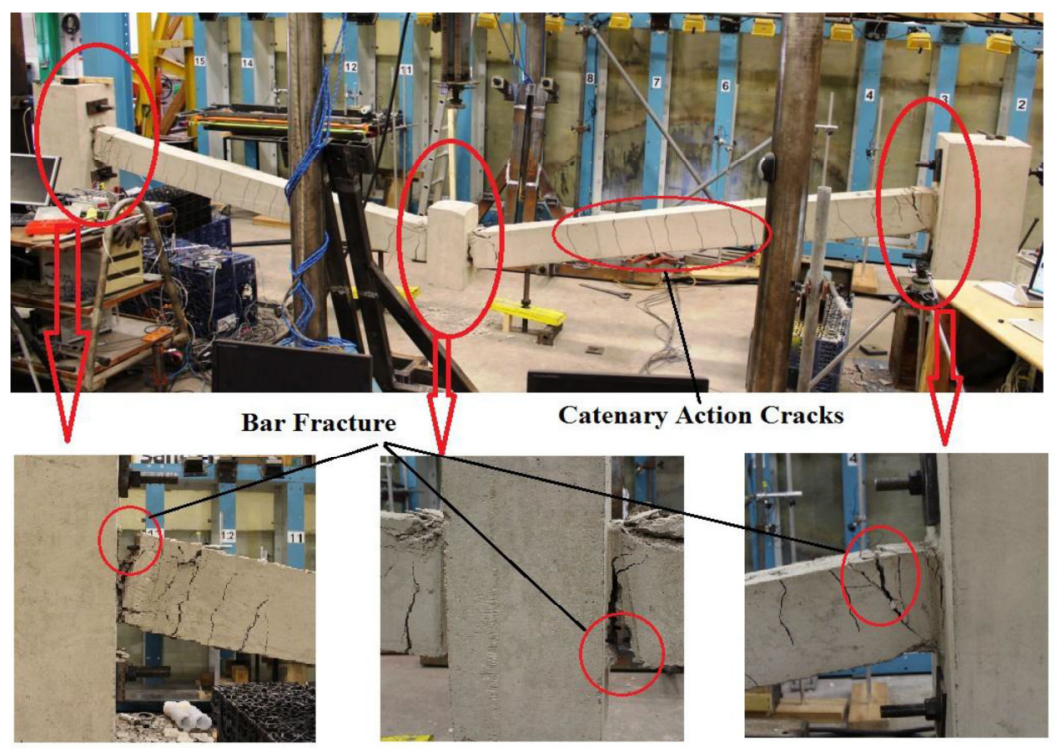

Fig. 12 - Crack pattern of specimen SS-1 at catenary action

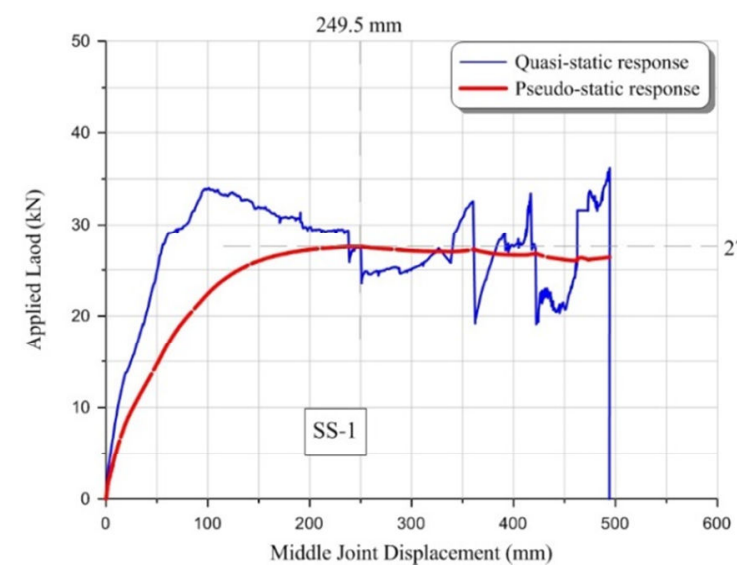

(a)

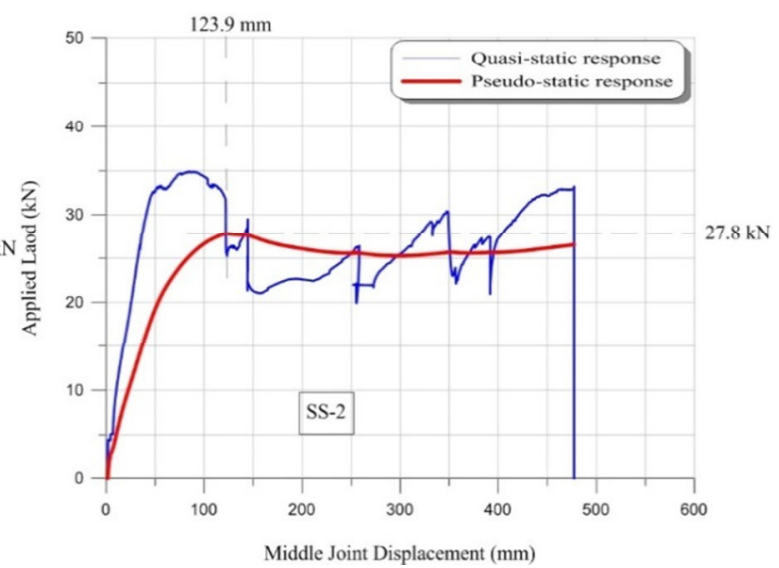

(b)

Fig. 13 - Non-linear Pseudo-Static response of specimens (a) SS-1 and (b) SS-2

The progressive collapse capacity for specimen SS-1 and SS-3 are 27.5 and $27.8 \mathrm{kN}$ with a corresponding middle joint displacement of 249.5 and $123.9 \mathrm{~mm}$ respectively as shown in Figure 13. This means that a total collapse will occur if the load increased beyond the load of $27.5 \mathrm{kN}$ and the deflection cannot then be predicted for specimen SS-1. The middle joint displacement corresponding to the maximum progressive collapse capacity occurs within the deflection range of compressive arch action. This means that the specimen was not able to increase its progressive collapse capacity into the catenary action stage and benefit from this structural action.

The MJD for SS-1 was much larger for specimen SS-2. This can be related to the difference in concrete compressive strength, which is larger for SS-2 than for SS-1. Concrete members with larger concrete compressive strength may fail in brittle mode failure, while concrete members with smaller concrete compressive strength may have inherent ductility.

It is clear from Figures 13, that the first peak pseudo-static resistance coincided with the first fracture of reinforcing bars in each specimen, indicating that bar fracture weakens progressive 
collapse resistance. The overall trends of pseudo-static responses were similar to those of quasi-static responses, but it is remarkable that the large catenary action capacities obtained from quasi-static tests were significantly reduced under dynamic situations.

\section{TEST RESULTS AT LOCAL LEVEL}

In order to investigate the development of internal forces within the beam sections, several strain gauges were attached to the steel reinforcing bars at critical sections. Bar strain measurements, which can be converted to bar forces, can shed light on the contributions of reinforcing bars to mobilization of different mechanisms. Figure 7 shows the layout of strain gauges along the beam length.

It was noticed during the tests, that the strain readings of most steel bars did not return to zero value after the fracture of these bars. This was due to the residual strains in the steel bars and the fracture does not occur at the location of strain gauges. It should be mentioned that the bar forces calculated are relative to the initial conditions rather than absolute values due to the presence of initial strains in the steel bars.

The general trend of bar force - MJD relationship for SS-1 and SS-2 were quite similar. Therefore, the relationship between bar forces and MJD for specimen SS-1 only will be presented in this section. Figure 14 shows the relationship between bar forces and MJD for specimen SS-1.

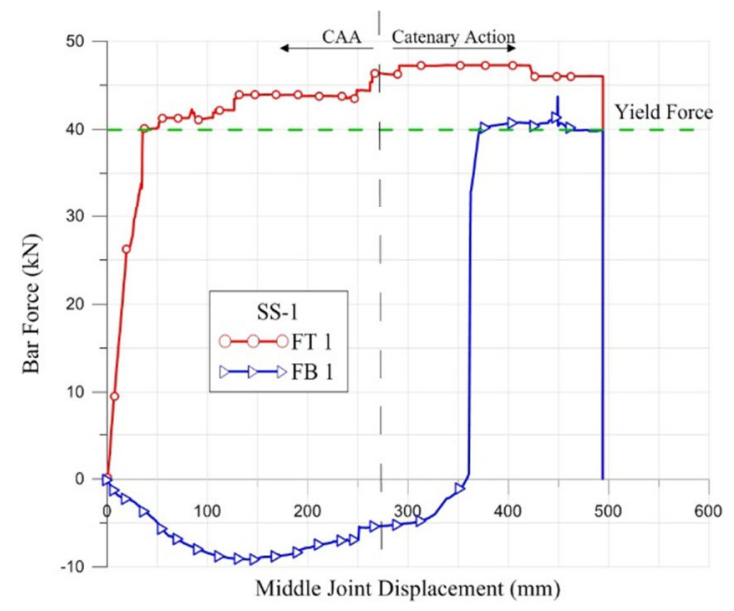

(a)

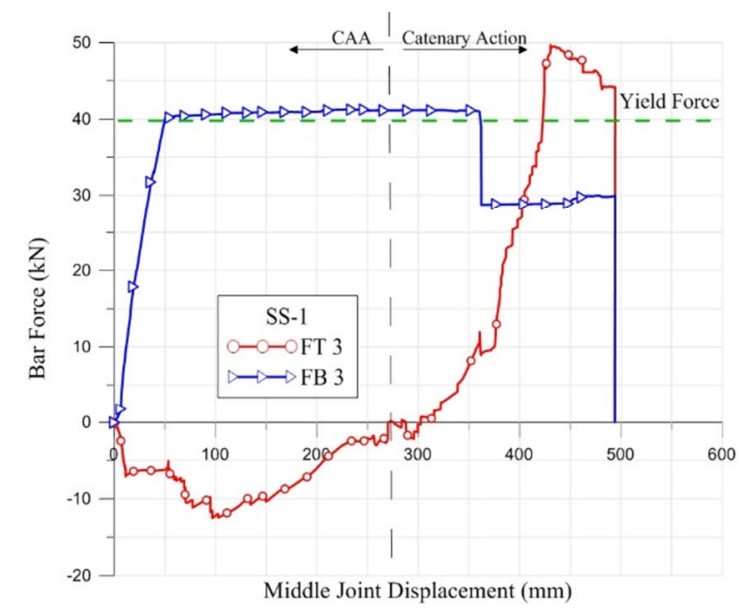

(c)

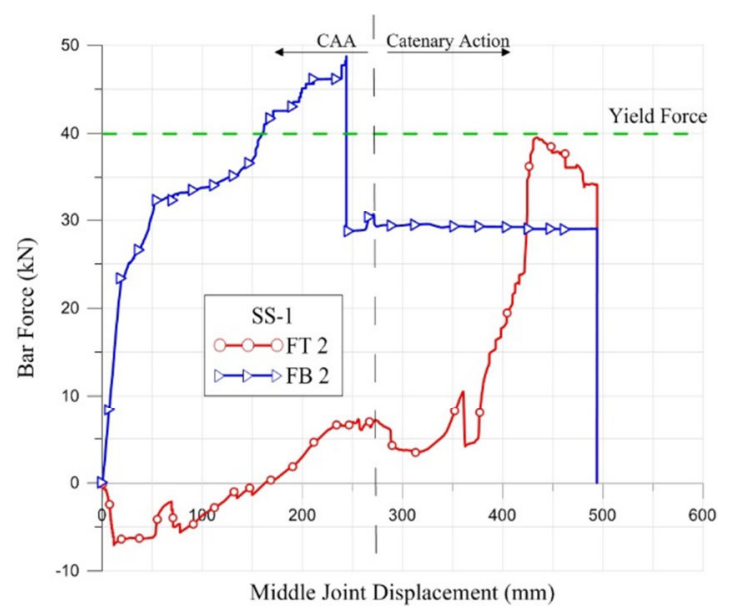

(b)

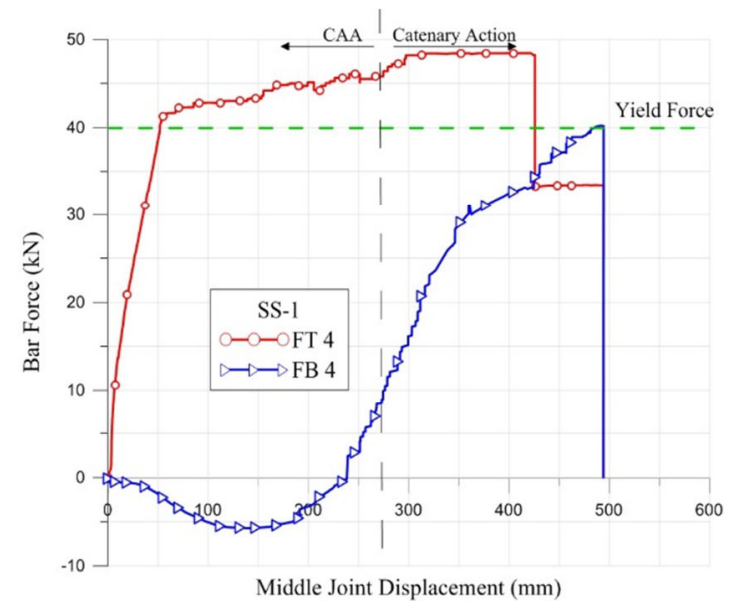

(d)

Fig. 14 - Bar forces vs. MJD for specimen SS-1 
The designations FT1 and FB1 refer to the force of the top and bottom bars at section 1 (see Figure 7). It can be seen from Figures 14(a-d), the tensile forces during catenary action were carried only by the bottom bars at the beam ends, and only by the top bars at the middle joint interfaces. It is also clear from Figure 14 that the tensile forces developed during catenary action were carried only by steel bars, while the contribution of concrete to the compression forces at CAA was about $50 \%$.

At the early stages of loading, the bottom bars yielded at section 2 and 3 , followed by fracture at both sections as shown in Figures 14 (b) and (c). This means, that the bottom bars are more vulnerable at early stages in the event of progressive collapse. At the mid stages of loading, it can be seen that the top bars are still carrying the loads at these sections, while at advanced stages of loading, both top and bottom bars were fractured at two sections at least.

\section{NUMERICAL STUDY}

In the event of progressive collapse, large deflections, plastic hinge formation, concrete crushing, steel bar slippage, steel bar pull-out and bar fracture may occur. Therefore, both geometrical and material nonlinearities must be included and considered in the analysis of RC structures subjected to abnormal loads which may leads to progressive collapse. Therefore, it is not efficient to use detailed a finite element (FE) model to simulate the behaviour of RC structures under catenary action including geometrical and material nonlinearities and all possible failure modes. This is because of the high computational cost for nonlinear analysis of large structures such as a multistorey reinforced concrete building which is always exorbitant since a large number of finite elements are needed to partition the structure to obtain reasonably accurate predictions of the structural response (Hartmann et al., 2008).

It should be noted that modeling geometric and material nonlinearities using the finite element method almost always requires repeating updates of the tangent stiffness matrix and solutions of the corresponding linear equation systems, which is the most time-consuming step in the iterative numerical scheme. However, in many practical problems involving nonlinear analysis of large-scale structures, the material nonlinearity phenomena are usually localized at certain critical structural members and may not dramatically spread throughout the whole structure. Thus, at each load increment, the computational effort spent on assembling the tangent stiffness matrix calculation and updating of structural members properties could be avoided using the macro-model approach to simulate the behaviour of RC structures under catenary action (Long, 2013).

\section{MACRO-MODEL APPROACH}

In order to get better understanding of the beam-column joint behaviour with effective and efficient computational cost a macro-model approach has been used to simulate $\mathrm{RC}$ structures under seismic loading and progressive collapse (Fleury et al., 2000, Lowes et al., 2005, Lowes et al., 2003, Mitra, 2007, Bao et al., 2008).

The main concept of the Macro-Model approach is to decompose multiple complicated behaviour of RC beam-column joint into several simple components such as flexural, axial, bond-slip, interface shear and shear panel behaviour. Each component can be characterized by an equivalent set of nonlinear springs, which can be defined by a relationship between force and displacement of each component. 
For a 2D RC beam-column joint, various component-based approaches had been proposed to predict the joint deformation behaviour (Alath and Kunnath, 1995, Youssef and Ghobarah, 2001, Lowes et al., 2003, Bao et al., 2008). Figure 15 shows the typical configuration of the joint model adapted by Lowes et al., which comprises eight bar force-slip spring components to simulate axial loads carried by the section of the structural member. The springs represent the stiffness and strength loss due to the potential anchorage failure of beam and column longitudinal reinforcement embedded into the joint, and the coupled action of compression and tension forces at each section represents the flexural strength of the RC beam. In addition, there are four interface shear components to simulate the loss of shear transfer capacity due to shear failure at the beam-joint and the column-joint interfaces.

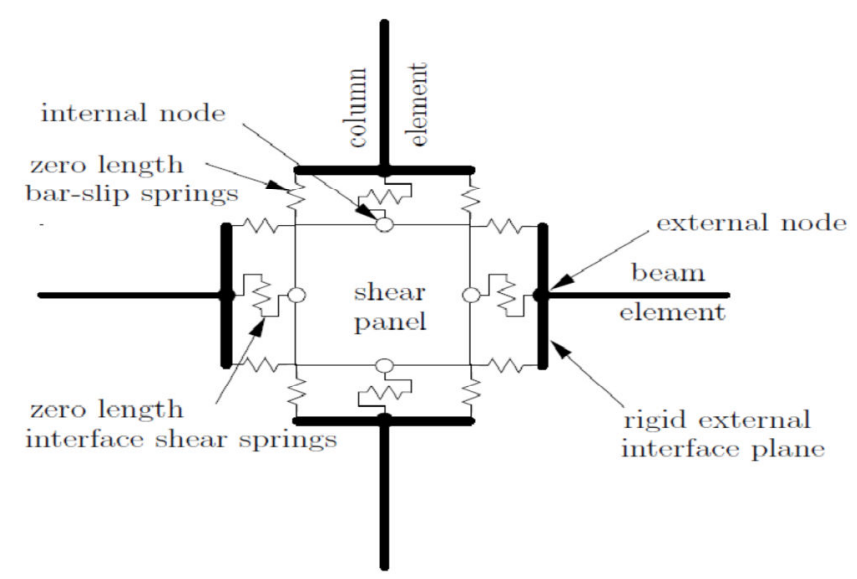

Fig. 15 - Lowes et al's joint model (Lowes et al., 2003)

According to the concept of designing columns stronger than beams, the joint model proposed by Lowes and Altoontash can be modified or reduced by assuming a rigid connection between column and beam. Therefore, bar force-slip springs of column-joint can be deleted from the model. Based on experimental tests, it is clear that there is no failure in the shear panel. Therefore it is assumed as a rigid panel. The new proposed model shown in Figure 16 comprises of three types of elements, (1) Bar force-slip springs $\left(S_{c o}\right.$ and $\left.S_{t n}\right)$, these springs are able to simulate beam axial compression or tension forces that develop through the beam under column removal or any applied load. In addition, the coupled action of these springs will simulate the bending moment capacity of the beam section at the critical sections. (2) Shear springs $\left(S_{s h}\right)$, which simulates shear forces developed at joint interfaces of beam-joint panel. (3) Rigid members, these members are able to simulate the rigid frame of beams at non-critical locations.

From experimental tests, it was evident that the bar force-slip spring is the most important and critical element in the Macro-model approach. This can significantly influence the structural behaviour of RC sub-assemblages, and maximum load capacity of these sub-assemblages under compressive arch action and catenary action. Therefore it is crucial to obtain the spring properties and calibrate the values of force-deformation of these springs to obtain an accurate representation of the structural behaviour of RC beam column sub-assemblages. 


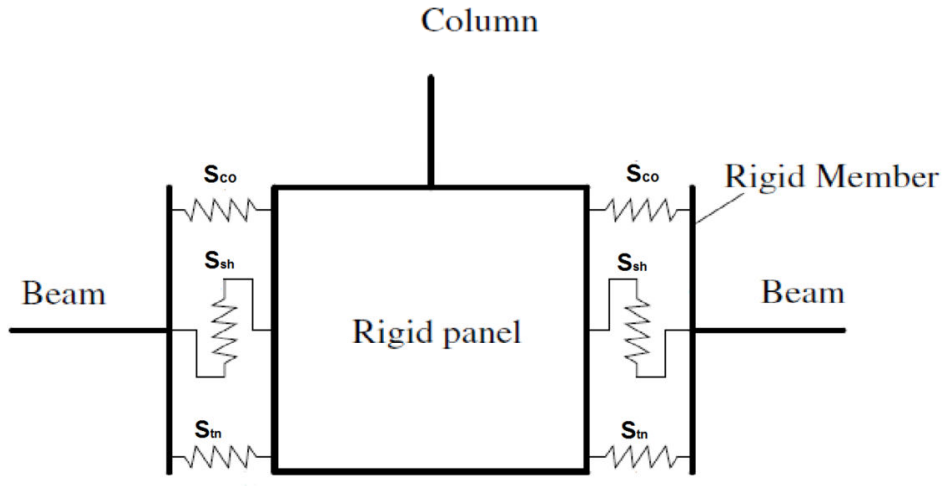

Fig. 16 - Proposed model

\section{SPRING PROPERTIES}

Spring properties for $S_{c o}$ and $S_{t n}$ can be obtained through bond-slip relationships between steel and concrete. Based on the approach proposed by Lowes (Lowes et al., 2005), stress-slip can be calculated and then converted into force-deflection relationship for the springs. Lowes assumed (1) a uniform bond stress distribution along the length of the rebar, (2) the constitutive model of steel bars is bilinear (3) there is a sufficient embedment length of steel bar so that the slip is zero at zero stress point. Figure 17 shows an idealization of the bond stress and resulting bar stress distribution for an anchored bar loaded beyond yield. Based on the previous assumption, Lowes defined the stress - slip relationship as follows:

For $f_{s}^{\prime}<f_{y}$

Slip $=\int_{0}^{l f s} \tau_{E} \frac{\pi d_{b}}{A_{b}} \cdot \frac{1}{E} x d x=2 \frac{\tau_{E}}{E} \cdot \frac{l f s^{2}}{d_{b}}$

For $f_{s}^{\prime}>f_{y}$

Slip $=\int_{0}^{l e} \frac{4}{d_{b}} \frac{\tau_{E}}{E} x d x+\int_{0}^{l e+l y} \frac{f_{y}}{E}+\tau_{y} \frac{4}{d_{b}} \frac{1}{E_{h}}\left(x-l_{e}\right) d x$

Slip $=2 \frac{\tau_{E}}{E} \cdot \frac{l e^{2}}{d_{b}}+\frac{f_{y}}{E} l y+2 \frac{\tau_{y}}{E_{h}} \cdot \frac{l y^{2}}{d_{b}}$

With

$l_{f s}=\frac{f_{s} d_{b}}{4 \tau_{E}} \quad, l_{e}=\frac{f_{\boldsymbol{y}} d_{b}}{4 \tau_{E}} \quad, l_{y}=\frac{\left(f_{s}-f_{y}\right) d_{b}}{4 \tau_{y}}$

Where $f_{s}$ is the bar stress at the point of investigation, $E$ is the steel modulus of elasticity, $f_{y}$ is the steel stress at yield point, $E_{h}$ is the steel hardening modulus, $\tau_{E}$ is the bond strength for elastic steel, $\tau_{y}$ is the bond strength for yielded steel, $A_{b}$ is the nominal bar area, and $d_{b}$ is the nominal bar diameter. $l_{e}$ and $l_{y}$ define, respectively, the lengths along the reinforcing bar for which steel stress is less than and greater than the yield stress. 


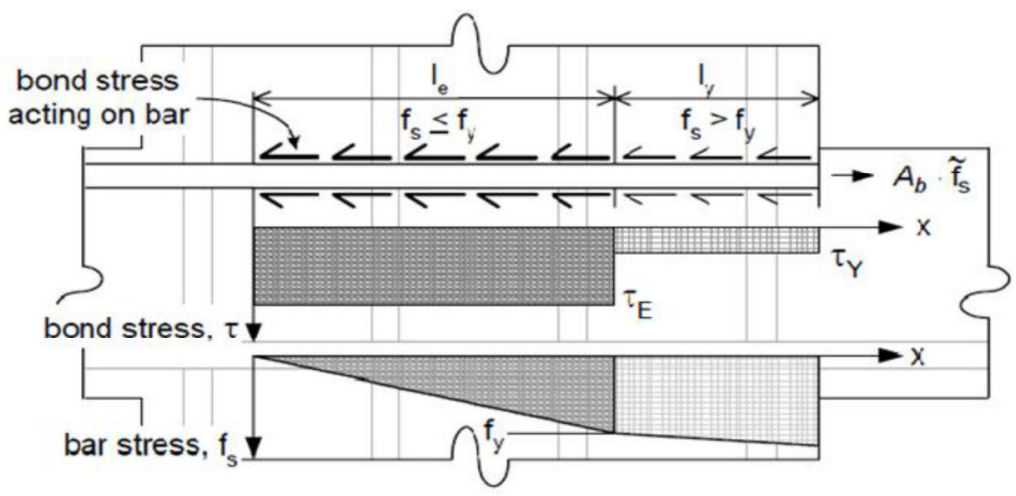

Fig. 17 - Bond and bar stress at exterior joint (Lowes et al., 2003)

Long (Long, 2013) has derived formulae to determine the relationships of slip and bar stress for a continuous bar with a short embedment length. For reinforcement, engineering stress was used so that the cross-sectional area of reinforcement remained constant. Then the spring force was obtained by multiplying the bar stress with the area of a reinforcement layer. The compressive branch of spring $S_{c o}$ is determined by the usual assumptions in RC design, such as the limit compressive strain of 0.003 for concrete and a rectangular stress block distribution in compression. According to these assumptions, a linear relationship between compressive spring force and compressive bar stress is obtained. Similar to tensile bar stress-slip derivation, the compressive bar stress-slip relationship can be obtained and further used to determine the relationship of compressive spring force and slip.

Based on many experimental tests, constant uniform bond strength for elastic and inelastic stages has been evaluated by many researchers. Table 4 lists the empirical values for bond stress for elastic $\left(\tau_{E}\right)$ and inelastic $\left(\tau_{y}\right)$ values, and also for tension and compression, which has been adapted by many researchers.

Table 4 - Empirical values for bond strength

\begin{tabular}{|c|c|c|c|c|}
\hline \multirow{2}{*}{ Model } & \multicolumn{4}{|c|}{ Average Bond Strength (MPa) } \\
\cline { 2 - 5 } & \multicolumn{2}{|c|}{ Tension } & \multicolumn{2}{|c|}{ Compression } \\
\cline { 2 - 5 } & Elastic $\tau_{E}$ & Inelastic $\tau_{y}$ & Elastic $\tau_{E}$ & Inelastic $\tau_{y}$ \\
\hline (Sezen and Setzler, 2008) & $1.0 \sqrt{\boldsymbol{f}_{\boldsymbol{c}}}$ & $\mathbf{0 . 5} \sqrt{\boldsymbol{f}_{\boldsymbol{c}}}$ & & \\
\hline (Lowes et al., 2003) & $1.8 \sqrt{\boldsymbol{f}_{\boldsymbol{c}}}$ & $\mathbf{0 . 4} \sqrt{\boldsymbol{f}_{\boldsymbol{c}}}$ & $2.2 \sqrt{\boldsymbol{f}_{\boldsymbol{c}}}$ & $3.6 \sqrt{\boldsymbol{f}_{\boldsymbol{c}}}$ \\
\hline (Eligehausen et al., 1982) & $2.0 \sqrt{\boldsymbol{f}_{\boldsymbol{c}}}$ & $\mathbf{0 . 5} \sqrt{\boldsymbol{f}_{\boldsymbol{c}}}$ & $3.1 \sqrt{\boldsymbol{f}_{\boldsymbol{c}}}$ & $3.1 \sqrt{\boldsymbol{f}_{\boldsymbol{c}}}$ \\
\hline
\end{tabular}

Based on the mechanics of material, a force - deformation envelope can be derived and used as shear spring properties. Based on beam geometry and material properties, the force deformation equation can be obtained as follows:

$\tau=G \gamma$

Where $\quad \tau=\frac{V}{A} \quad, \quad \gamma=\frac{\delta}{L}, G=\frac{E}{2(1+v)}$ 
Substituting in equation (3)

$$
V=\frac{A_{c} E_{c}}{2(1+v)} \frac{\delta}{L}
$$

Where $V$ is shear force acting on the beam section, $A_{c}$ is the area of beam section and it is equal to $(b \times d), E_{c}$ is concrete modulus of elasticity, $\delta$ is shear deformation, $v$ is Poisson's ratio of concrete and $L$ is the shear span.

Equation (4) represents concrete contribution for RC beams in shear strength neglecting the contribution of steel ties and longitudinal steel reinforcement. Conventional design provides sufficient shear strength for RC members to prevent shear failure. Due to this fact, neglecting the steel contribution for shear strength will not affect the analysis results at this stage of numerical analysis.

\section{IMPLEMENTATION OF THE MACRO-MODEL IN FEM}

A finite element model has been developed using the finite element program ANSYS 11.0, and static tests have been carried out taking into account geometric and material non-linearity to investigate the structural mechanisms following the removal of the middle column.

The finite element modelling includes the modelling of the specimens designed for static tests in experimental program. The same dimensions, steel reinforcement and mechanical properties for both concrete and steel from experimental work were used. Figure 18 shows the model layout with element types. Beams and columns were modelled by using 2D beam element (BEAM3), which is available in ANSYS 11.0 element library. This element is a line element with two nodes at the ends with tension, compression and bending capabilities. This element also requires the cross sectional area $A$ and the second moment of area $I$ to be defined. In addition, material properties including elastic modulus, Poison's ratio and mass density were defined.

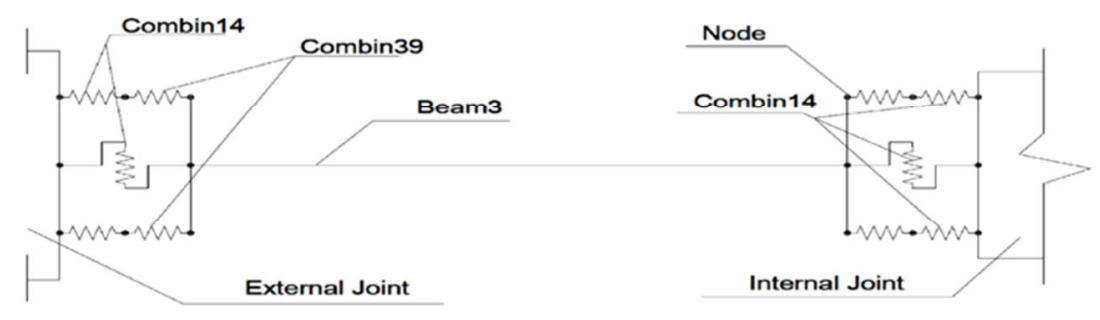

(a)

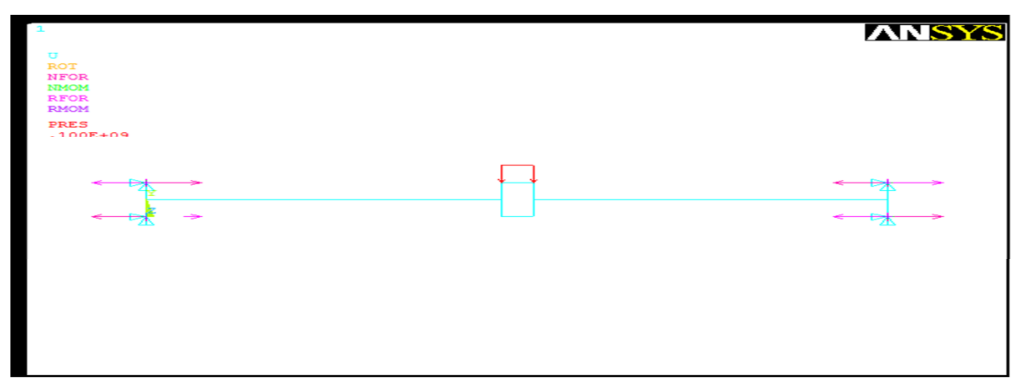

(b)

Fig. 18 - (a) Schematic of macro-model configuration, and (b) ANSYS macro-model 
In order to take material non-linearity into account, a second element was used. The nonlinear element (COMBIN39), which is available in ANSYS 11.0 element library, was used at critical sections to simulate sections that will undergo non-linearity. (COMBIN39) is defined by a force-deflection relation. No material properties are required for this element.

To capture bar fracture or pull-out failure linear element (COMBIN14) was used. The element is defined by two nodes, a spring constant $(k)$ and damping coefficients $\left(c_{v}\right)_{1}$ and $\left(c_{v}\right)_{2}$. The damping capability is not used for static or un-damped modal analysis. Due to element capability of Birth and Death feature included in ANSYS, this element was used to capture bar fracture in the analysis. In addition, (COMBIN14) was used as a shear spring to simulate shear capacity of RC beam section.

The ANSYS software requires that each non-linear spring should have a force-deformation input data as the element properties, and no limit for the number of data points. To simplify the analysis and reduce time costs, the non-linear force-deformation relationship of springs $\left(S_{c o}\right.$ and $\left.S_{t n}\right)$ were simplified into tri-linear relationships. Figure 19 shows the critical points of the reduced force-deformation relationship.

The values of critical points shown in Figure 20 depend on many factors such as, steel reinforcement and concrete properties, detailing of steel bars and section properties. $F_{y}$ and $S_{y}$ represent steel bar yielding in tension and corresponding slip of steel bar respectively. $F_{u}$ and $S_{u}$ represent the smaller value of bar fracture or pull-out force and its corresponding bar slip. $F$ is chosen to be the average value between $F_{y}$ and $F_{u}$, and $S$ is the bar slip corresponding to the average value.

In the compression zone, $F_{1}, F_{2}$ and $F_{3}$ represent compression force at the point of concrete crushing, yielding of steel bars in compression and ultimate spring capacity with their corresponding values of bar slips $S_{1}, S_{2}$ and $S_{3}$.

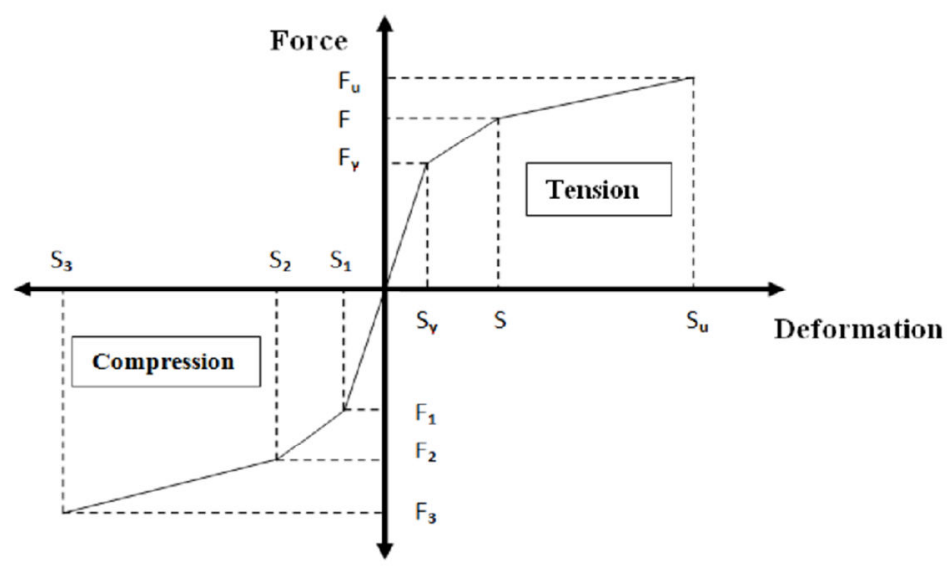

Fig. 19 - Bar force- deformation properties for springs $\left(\mathrm{S}_{\mathrm{tn}}\right.$ and $\left.\mathrm{S}_{\mathrm{co}}\right)$

The spring properties of $\left(S_{t n}\right)$ and $\left(S_{c o}\right)$ for specimens (SS-1 and SS-2) were obtained using tension bond strength proposed by Sezen and Setzler (Sezen and Setzler, 2008) and compression bond strength by Lowes et al. (Lowes et al., 2003). The reason for choosing bond strength proposed by Sezen and Setzler, was because these values will provide smaller capacity in order to provide safety when calculating the RC sub-assemblages progressive collapse capacity. 


\section{NUMERICAL RESULTS AND VALIDATION OF JOINT MODEL}

The macro-model approach outlined above was validated by comparing the structural behaviour results from numerical analysis with those obtained from experimental tests. The aim was to find out the capability of the proposed model to capture the structural behaviour of RC structures under middle column removal scenario and prediction of structural resistance capacities at both compressive arch action and catenary action and their corresponding deformations.

The load was applied at the middle joint by applying a static displacement controlled load with constant incremental value of $(1 \mathrm{~mm} / \mathrm{step})$ until the total failure of the specimens. Material nonlinearity was already included in the spring properties, while geometric nonlinearity was activated by using the large displacement option, which is one of the features in software package of ANSYS 11.0. All reactions and axial forces were recorded and plotted against vertical displacement of the middle joint. Displacement control was used to capture the softening in the structural behaviour of the sub-assemblages.

Figures 20 and 21 represent the structural behaviour of RC sub-assemblages in terms of applied load and axial forces vs. middle joint displacement for the specimens, which showed a good agreement between numerical and experimental results in terms of applied load and their corresponding deflections at both compressive arch and catenary action. It can be seen that the numerical results underestimate structural resistance at flexural phase. The reason for this difference is that the slip of steel bars in elastic phase was overestimated when calculating spring properties, while in the actual tests no slip occurred during the flexural phase. In addition, the friction between the restraints and the specimens could cause an increase in the experimental test results.

Unlike the experimental tests, the fracture of bottom reinforcement for both sides of middle joint occurred at the same time in numerical analysis, which was noticed for top reinforcement at both ends of the specimens. This was due to the imperfection during the construction of specimens and non-homogeneous material used such as concrete in experimental tests, while ANSYS considers perfect construction and uniform material properties.

However, the macro-model approach including bar stress-slip relationship can predict the overall structural behaviour of RC sub-assemblages during compressive and catenary phases.

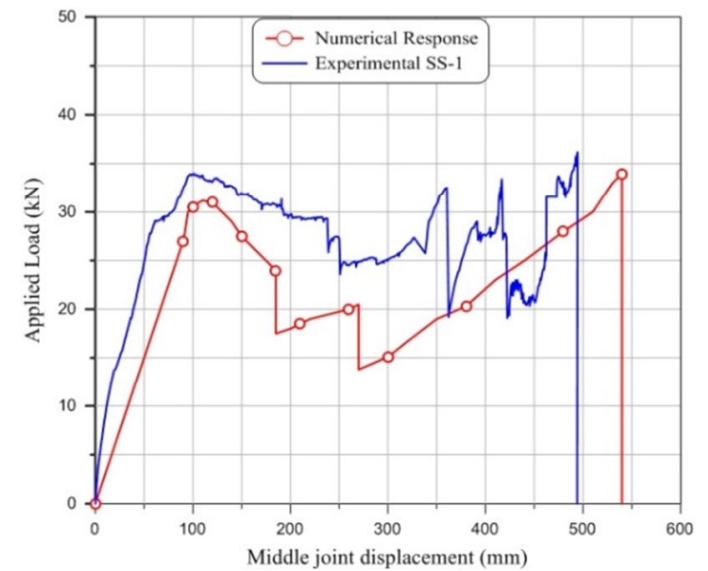

(a)

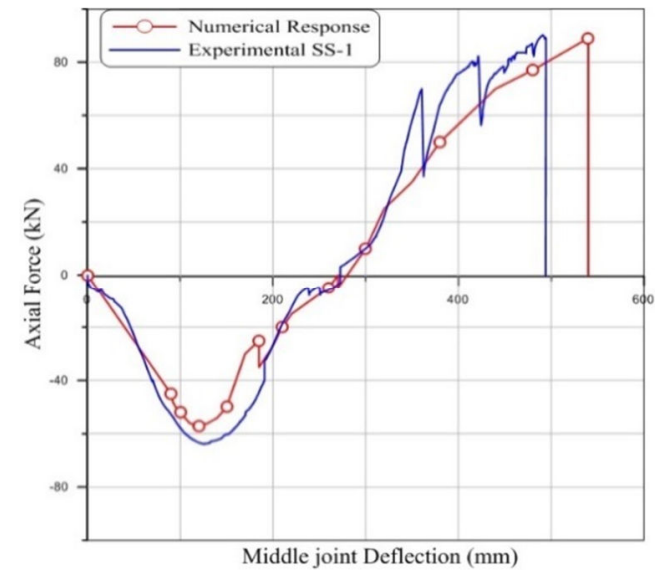

(b)

Fig. 20 - Comparison of experimental and numerical results for specimen SS-1 (a) Applied Load and (b) Axial forces 


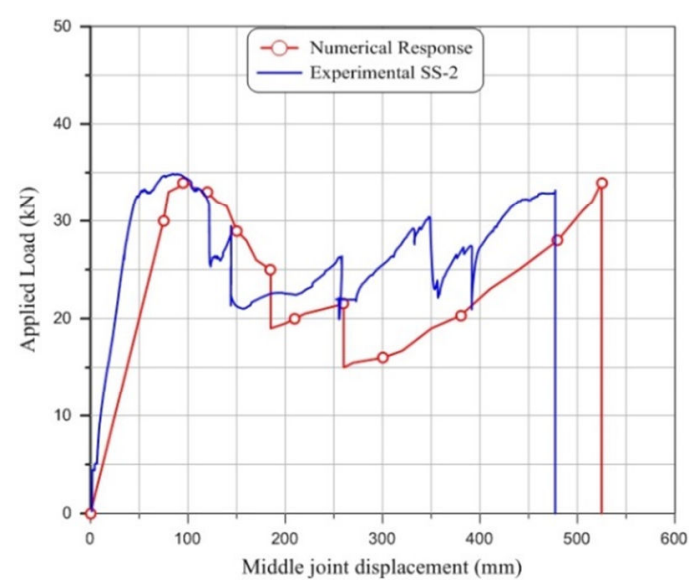

(a)

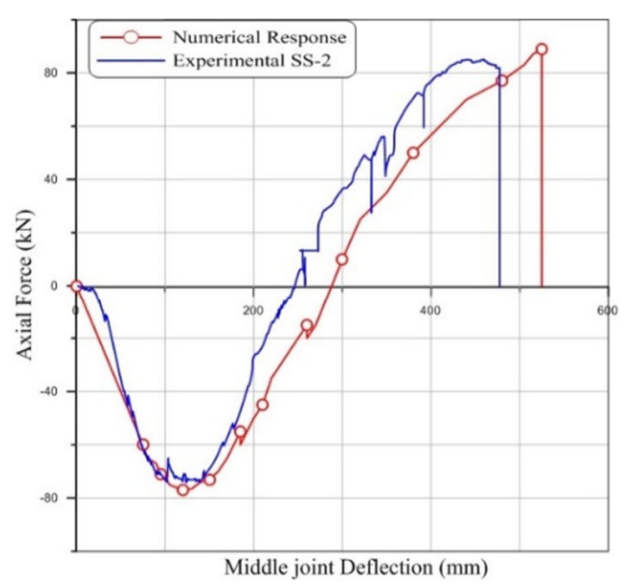

(b)

Fig. 21 - Comparison of experimental and numerical results for specimen SS-2 (a) Applied Load and (b) Axial forces

\section{CONCLUSIONS}

In this study, the structural behaviour of RC sub-assemblage specimens subjected to column loss scenario has been investigated. Thereafter, a numerical study was conducted to simulate the structural behaviour of these specimens. A macro-model was developed and proposed to simulate the critical sections at which the failure was occurred. Bond slip and bar fracture was included in the macromodel which was implemented in the finite element software package ANSYS 11.0.

Both specimens experienced three stages of resisting mechanisms, flexural, CAA and catenary action. The behaviour was dominated by flexure in the early stages of the response. With increased vertical displacement of the center column, resistance was provided through the development of compressive diagonal axial forces or "arching action" due to the restraint on axial elongation of the beams by the end columns. With further increase in the vertical displacement, the tensile axial forces developed in the beams and the behaviour was dominated by catenary action. There is no clear transition point from flexural to CAA due to the fact that the restraint beams can develop CAA even at early stages. While the transition point from CAA to catenary action was indicated by the change in axial forces from compression to tension. The onset of catenary action stage occurred at a MJD equal to $0.98 \mathrm{~h}-$ $1.09 h$. CAA capacity was $17.1 \%-21.4 \%$ larger than flexural capacity calculated based on the plastic hinge analysis. At catenary action stage, on the top of CAA the resisting capacity was increased by up to $6.5 \%$ for specimen SS- 1 .

The failure of the specimens was characterized by: (1) Crushing of concrete at compression zones during flexural action. (2) Development of flexural cracking during flexural and CAA. (3) Bar fracture at beam-column interfaces. (4) Large slippage between concrete and steel bars caused wide cracks at critical sections.

Test results at local level showed that the bottom bars experienced tensile strains at the specimen ends, and yielded in tension, during the last stage of the beam tensile membrane action, despite the fact that the bottom bars fractured earlier at the middle joint interfaces. This indicates that the increasing tensile stresses at the top bars, developed due to catenary action, were transferred to the bottom bars through concrete bond and remaining anchorage.

Macro-models consisting of beam and spring elements can accurately predict the response characteristics of RC beam-column sub-assemblages. 
Compared to experimental results, numerical results underestimate the applied load and axial forces throughout the beam. This can be explained by many factors related to experimental study, such as the presence of friction due to restraints and the imperfection of the construction of the specimens, and uncertainty ofmeasurement to explain the differences between experimental and numerical results.

\section{ACKNOWLEDGMENTS}

The authors gratefully acknowledge the funding by Iraqi cultural attaché in London-UK.

\section{REFERENCES}

[1]-ACI-318. Building code requirements for structural concrete (ACI 318-05) and commentary (ACI 318R-05). 2005. American Concrete Institute.

[2]-ALATH, S. \& KUNNATH, S. K. Modeling inelastic shear deformation in RC beamcolumn joints. Engineering Mechanics (1995), 1995. ASCE, 822-825.

[3]-ASTM 2002. ASTM C469-02 Standard Test Method for Static Modulus of Elasticity and Poisson's Ratio of Concrete in Compression. ASTM International.

[4]-ASTM 2009. ASTM C78-09 Standard test method for flexural strength of concrete (using simple beam with third-point loading). ASTM International.

[5]-BAO, Y., KUNNATH, S. K., EL-TAWIL, S. \& LEW, H. 2008. Macromodel-based simulation of progressive collapse: RC frame structures. Journal of Structural Engineering, 134, 1079-1091.

[6]-BS1881-116 1983 Testing concrete. Method for determination of compressive strength of concrete cubes.

[7]-BYFIELD, M., DE MATTEIS, G. \& DINU, F. 2007. Robust design of steel framed buildings against extreme loading. Proc. Cost C26, 253-267.

[8]-BYFIELD, M. \& PARAMASIVAM, S. 2007. Catenary action in steel-framed buildings. Proceedings of the ICE-Structures and Buildings, 160, 247-257.

[9]-CHOI, H. \& KIM, J. 2011. Progressive collapse-resisting capacity of RC beam-column sub-assemblage. magazine of concrete research, 63, 297-310.

[10]-DOD 2004. Design of Buildings to Resist Progressive Collapse. Unified Facilities Criteria (UFC) . Department of Defense September 2004.

[11]-ELIGEHAUSEN, R., POPOV, E. P. \& BERTERO, V. V. 1982. Local bond stress-slip relationships of deformed bars under generalized excitations.

[12]-FLEURY, F., REYNOUARD, J.-M. \& MERABET, O. 2000. Multicomponent model of reinforced concrete joints for cyclic loading. Journal of engineering mechanics, 126, 804-811.

[13]-GSA 2003. Progressive Collapse Analysis and Design Guidelines. U.S. General Services Administration.

[14]-HARTMANN, D., BREIDT, M., STANGENBERG, F., HÖHLER, S., SCHWEIZERHOF, K., MATTERN, S., BLANKENHORN, G., MÖLLER, B. \& LIEBSCHER, M. 2008. Structural collapse simulation under consideration of uncertaintyFundamental concept and results. Computers \& Structures, 86, 2064-2078. 
[15]-IZZUDDIN, B. 2005. A simplified model for axially restrained beams subject to extreme loading. International Journal of Steel Structures, 5, 421-429.

[16]-IZZUDDIN, B., VLASSIS, A., ELGHAZOULI, A. \& NETHERCOT, D. 2008. Progressive collapse of multi-storey buildings due to sudden column loss-Part I: Simplified assessment framework. Engineering Structures, 30, 1308-1318.

[17]-LONG, X. 2013. Numerical study on reinforced concrete beam-column frames in progressive collapse.

[18]-LOWES, L. N., ALTOONTASH, A. \& MITRA, N. 2005. Closure to "Modeling Reinforced-Concrete Beam-Column Joints Subjected to Cyclic Loading" by Laura N. Lowes and Arash Altoontash. Journal of Structural Engineering, 131, 993-994.

[19]-LOWES, L. N., MITRA, N. \& ALTOONTASH, A. 2003. A beam-column joint model for simulating the earthquake response of reinforced concrete frames, Pacific Earthquake Engineering Research Center, College of Engineering, University of California.

[20]-MITRA, N. 2007. An analytical study of reinforced concrete beam-column joint behavior under seismic loading. PhD dissertation, University of Washington.

[21]-ORTON, S. 2007. Development of a CFRP System to Provide Continuity in Existing Reinforced Concrete Structures Vulnerable to Progressive Collapse. Austin, Texas: The University of Texas at Austin, Department of Civil, Environmental and Architectural Engineering.

[22]-REGAN, P. 1975. Catenary Action in Damage Concrete Structures. ACI Special Publication, 48.

[23]-SADEK, F., MAIN, J. A., LEW, H. \& BAO, Y. 2011. Testing and analysis of steel and concrete beam-column assemblies under a column removal scenario. Journal of Structural Engineering, 137, 881-892.

[24]-SASANI, M. \& KROPELNICKI, J. 2008. Progressive collapse analysis of an RC structure. The Structural Design of Tall and Special Buildings, 17, 757-771.

[25]-SEZEN, H. \& SETZLER, E. J. 2008. Reinforcement slip in reinforced concrete columns. ACI Structural Journal, 105.

[26]-SU, Y., TIAN, Y. \& SONG, X. 2009. Progressive Collapse Resistance of AxiallyRestrained Frame Beams. ACI Structural Journal, 106.

[27]-YI, W.-J., HE, Q.-F., XIAO, Y. \& KUNNATH, S. K. 2008. Experimental study on progressive collapse-resistant behavior of reinforced concrete frame structures. ACI Structural Journal, 105.

[28]-YIN, Y. \& WANG, Y. 2005. Analysis of catenary action in steel beams using a simplified hand calculation method, Part 1: theory and validation for uniform temperature distribution. Journal of Constructional Steel Research, 61, 183-211.

[29]-YOUSSEF, M. \& GHOBARAH, A. 2001. Modelling of RC beam-column joints and structural walls. Journal of Earthquake Engineering, 5, 93-111.

[30]-YU, J. \& TAN, K.-H. 2013. Experimental and numerical investigation on progressive collapse resistance of reinforced concrete beam column sub-assemblages. Engineering Structures, 55, 90-106.. 